\title{
Life satisfaction, fear of death, and ego identity in elderly adults
}

\author{
NINA WOODS and KENNETH L. WITTE \\ University of Arkansas, Fayetteville, Arkansas 72701
}

\begin{abstract}
Erikson's eighth developmental stage, ego integrity.vs. despair, was examined using the Life Satisfaction Index-A (LSIA) as a measure of ego integrity, the Death Anxiety Scale (DAS) as a measure of despair, and the Ego Identity Scale (IIIS) as a measure of the successful resolution of the first six stages of psychosocial develor ment. Three hypotheses were tested: (1) A positive correlation would exist for performance on the LSIA and the EIS, (2) a negative correlation would exist for performance on the DAS and on the LSIA, and (3) a negative correlation would exist for performance on the DAS and on the EIS. The subjects were 100 men and women $61-89$ years of age. The first hypothesis was supported, and the second and third were supported with men but not with women.
\end{abstract}

Erikson's epigenetic theory of psychosocial development is one of the few theories that addresses development and change occurring throughout the life span. His postulation of a series of eight basic crises occurring sequentially provides a framework for looking at lifelong development. Erikson (1950) said that personality development is determined by the degree of successful resoultion achieved at each stage or crisis. Resolution of each crisis is expressed as a point on a continuum rather than as an absolute and is considered to influence the resolution of all subsequent crises. The eighth stage outlined by Erikson, ego integrity vs. despair, was the focus of this study.

Considering the scarcity of theoretical foundations for predicting and explaining changes in personality throughout adulthood, surprisingly little research has been done on the last developmental stage postulated by Erikson. This crisis, generally occurring in old age, involves the conflict between ego integrity and despair and, when resolved successfully, results in wisdom. Those individuals who fall to despair are bitter, feel that life treated them unjustly, are alarmed that they have too little time left to achieve their personal goals, and fear death. Those who attain ego integrity are characterized by self-acceptance and tolerance for the life-styles of others, and yet they are decisive in defense of their own modes of living and feel happy and satisfied with their lives. The resultant virtue, wisdom, refers to the knowledge of life realized through the experience and conquest of life's experiences.

Although Erikson's conceptualizations of this eighth stage have not been directly tested, results of studies

This article is based on a thesis submitted by the first author in partial fulfillment of the requirements for the MA degree at the University of Arkansas. Requests for reprints can be sent to either author, Department of Psychology, University of Arkansas, Fayetteville, Arkansas 72701. concerned with personality in old age can be interpreted as providing support for some aspects of the theory (Neugarten, Crotty, \& Tobin, 1964; Reichard, Livson, $\&$ Peterson, 1962). Neugarten et al. interviewed and tested men and women 50-90 years of age and then rated these individuals on 45 personality variables. Factor analysis revealed for each sex six basic personality types, the most important one being integrity. Neugarten et al. described this personality characteristic as involving a continuum of adjustment, and their description seems congruent with Erikson's continuum of integrity vs. despair. Those individuals classified as integrated were found to score higher than others on a measure of life satisfaction.

Reichard et al. (1962) interviewed men ranging in age from 55 to 84 years. Half were still working, and the other half were retired. The interview data were used to derive ratings for a number of personality traits, and the men were scored for being either high or low in acceptance of aging. The latter group was composed of two subgroups. The larger subgroup consisted of men who blamed others for their miseries, and those in the second subgroup were "self-haters" who were full of despair-both seemingly corresponding to what Erikson indicated would happen without proper resolution of the final developmental crisis.

Ego integrity and despair, as defined by Erikson, are broad and complex concepts that have been difficult to quantify and research. In order to investigate the presence or absence of these attributes in the elderly and their relationship, it may be helpful to investigate major components of ego integrity and of despair that Erikson outlined as present at each end of the continuum. The present study attempted to demonstrate the validity of ego integrity and despair as opposing attributes of the elderly and to provide support for Erikson's theory. The variables of fear of death and life satisfaction were utilized to examine Erikson's concepts of despair and ego 
integrity. While these two variables were not intended to represent a comprehensive measure of these complex concepts, according to Erikson's (1959) descriptions of ego integrity and despair and the findings of Neugarten et al. (1964), life satisfaction would seem to be a vital, representative component of ego integrity and fear of death would seem to provide a central component of despair.

Erikson's theory predicts a negative correlation between integrity and despair; this study attempted to test this prediction using measures of life satisfaction and fear of death. The Life Satisfaction Index-A (LSIA), developed by the Kansas City Study of Adult Life (Neugarten, Havighurst, \& Tobin, 1961), was used to measure life satisfaction; fear of death was measured using Templer's (1970) Death Anxiety Scale.

A final purpose of this study was as follows. Erikson (1959) stated that the successful or unsuccessful resolution of earlier conflicts determined or strongly affected the success in resolving subsequent conflicts. This statement was investigated by examining the resolution of earlier conflicts and their relationships to the individual's level of life satisfaction and of fear of death. It was predicted that those who had successfully resolved the previous conflicts would have a higher life satisfaction and a lower fear of death. The resolution of earlier conflicts was measured by using the Ego Identity Scale developed by Rasmussen (1964).

\section{METHOD}

\section{Subjects}

The subjects were 71 women and 29 men aged $61-89$ years. They were participating in a nutrition program for the elderly in a county in northwest Arkansas and were from either small towns or rural areas. Demographic information regarding the subjects is presented in Table 1 .

\section{Measures}

Life satisfaction was measured with 18 of the 20 items of the LSIA, which is derived from the Life Satisfaction Rating (Neugarten et al., 1961). The two discarded items were those found by Adams (1969), using factor analysis, to have the lowest commonality with the one major factor associated with the LSIA item, life satisfaction. It should be noted that Adams concluded that the LSIA provides an adequate measure of life satisfaction for elderly subjects residing in small towns and rural areas.

Fear of death was measured using the Death Anxiety Scale developed by Templer (1970). This scale consists of 15 statements, and subjects are asked whether they agree or disagree with each.

The Ego Identity Scale, developed by Rasmussen (1964), was used to measure successful resolution of the first six stages of development as outlined by Erikson. Assessment of the resolution of the first seven stages was not possible because no measure of the crisis of generativity vs. stagnation has been reported in the literature, to our knowledge. Rasmussen's scale consists of six statements reflecting successful resolution and six statements reflecting unsuccessful resolution for each of the six stages of development, resulting in 72 items. To avoid a response set, half of the items were cast to require a positive response and half to require a negative response. Five of the 72 items were altered slightly in order to be more appropriate for elderly adults.

Self-perceived health was assessed by simply asking subjects the following question: "Would you say your health, in general, is excellent, good, fair, or poor?" This technique has been successfully used by others (e.g., Spreitzer \& Snyder, 1974).

\section{Procedure}

The experimenter (N.W.) visited the nutrition centers several times before beginning the interviews in order to allow the participants to become more comfortable with the interviewer. The LSIA, the Death Anxiety Scale, and the Ego Identity Scale were presented to each participant. Other information collected concerned the participant's age, sex, and years of education. The LSIA and the Ego Identity Scale were alternately presented first and last; Templer's Death Anxiety Scale was the middle test in each administration to decrease the likelihood of any negative emotional aftereffects. Those who were unable to read the questionnaire because of poor eyesight, difficulty in concentrating, or lack of reading skills were presented the statements verbally.

\section{RESULTS}

The four levels of self-perceived health-excellent, good, fair, and poor-were assigned numerical values of four, three, two, and one for the purpose of computing their correlations with the other variables. The variable identified as years of education referred to the highest grade of school completed by the individual or, if more than a high school education was obtained, to the total number of years of education completed. The means and standard deviations of each demographic and dependent variable are presented in Table 1 for the entire sample and for each sex.

Several Pearson product-moment coefficients were computed to test the predictions of the study. As predicted, a positive correlation was found between life satisfaction and ego identity $[\mathrm{r}(98)=.59, \mathrm{p}<.001]$. Analysis of the data separately by sex revealed reliable correlations for both the 71 women $[\mathrm{r}(69)=.61$, $\mathrm{p}<.001]$ and the 29 men $[\mathrm{r}(27)=.52, \mathrm{p}<.01]$. Contrary to expectations, fear of death was not reliably correlated with either ego identity $(r=-.16)$ or life satisfaction $(r=-.08)$. However, when the data were analyzed separately by sex, reliable correlations were found for men $(r=-.42$ and -.40 , respectively; $p<.05$

Table 1

Means and Standard Deviations on Each Demographic and Dependent Variable

\begin{tabular}{|c|c|c|c|c|c|c|}
\hline \multirow[b]{2}{*}{ Variable } & \multicolumn{2}{|c|}{$\begin{array}{c}\text { Total } \\
(\mathrm{N}=100)\end{array}$} & \multicolumn{2}{|c|}{$\begin{array}{l}\text { Women } \\
(\mathrm{N}=71)\end{array}$} & \multicolumn{2}{|c|}{$\begin{array}{c}\text { Men } \\
(N=29)\end{array}$} \\
\hline & Mean & SD & Mean & SD & Mean & SD \\
\hline Age & 72.98 & 6.28 & 72.69 & 6.42 & 73.69 & 5.98 \\
\hline Education & 10.01 & 3.36 & 10.86 & 3.14 & 7.93 & 2.99 \\
\hline Health & 2.61 & .80 & 2.66 & .75 & 2.48 & .91 \\
\hline Life Satisfaction & 12.21 & 3.20 & 12.38 & 3.23 & 11.79 & 3.16 \\
\hline Fear of Death & 5.00 & 2.74 & 5.01 & 2.56 & 4.97 & 3.19 \\
\hline Ego Identity & 49.86 & 9.97 & 50.41 & 10.15 & 48.52 & 9.55 \\
\hline
\end{tabular}


in each case), but not for women $(r=-.05$ and .07 , respectively).

With respect to these sex-related differences, the only demographic. variable on which the men and women differed significantly was years of education $[t(98)=$ $4.28, \mathrm{p}<.001]$. A partial correlation was conducted in order to investigate the possibility that it was the difference in level of education that accounted for the sex-related differences. The correlation between fear of death and ego identity was now significant for the entire sample $(r=-.29, p<.01)$ and was still significant for the men $(r=-.61, p<.001)$; however, the correlation was still nonsignificant for the women $(\mathrm{r}=-.16)$. The correlation between fear of death and life satisfaction was still nonsignificant for the entire sample $(r=-.15)$ and for the women $(r=.02)$; the correlation was still reliable for men $(r=-.51, \mathrm{p}<.001)$. These analyses would seem to indicate that differences in education probably do not account for the observed sex-related differences.

A number of secondary correlational analyses were conducted for heuristic reasons. Life satisfaction was reliably correlated with self-perceived health for the entire sample $(r=.46, p<.001)$ and for the women $(r=.52$, $\mathrm{p}<.001)$, but the correlation was only marginally significant for the men $(\mathrm{r}=.35, \mathrm{p}<.07)$. Life satisfaction was positively correlated with education for the entire group $(\mathrm{r}=.36, \mathrm{p}<.001)$ and for the women $(\mathrm{r}=.36$, $\mathrm{p}<.01$ ), but, again, the correlation was only marginally significant for the men $(r=.36, p=.06)$. The relatively smaller size of the sample of men and the resultant fewer degrees of freedom necessitated that higher correlations be obtained to reach significance at the .05 level for men than for women. Life satisfaction did not correlate reliably with age for the group as a whole $(r=-.14)$ or for either the women $(\mathrm{r}=-.14)$ or the men $(\mathrm{r}=-.13)$.

Ego identity was positively correlated with selfperceived health for the entire group $(r=.38, p<.001)$ and for the women $(r=.38, p<.001)$. Surprisingly, the corresponding correlation for men was negative $(\mathrm{r}=-.23)$; however, this value was not significant. Ego identity was reliably correlated with education for the group $(\mathrm{r}=.52, \mathrm{p}<.001)$ and for both women $(\mathrm{r}=.43$, $\mathrm{p}<.001)$ and men $(\mathrm{r}=.49, \mathrm{p}<.01)$ separately. A significant negative correlation was obtained between ego identity and age for the entire sample $(r=-.27$, $\mathrm{p}<.01)$ and for the women $(\mathrm{r}=-.25, \mathrm{p}<.05)$, but the correlation was only marginally significant for the men $(r=-.32, p=.09)$. However, when the effects of education are partialled out, the correlations between ego identity and age are all nonsignificant. Thus, the relationship between ego identity and education seems to account for the relationship between ego identity and age.

A reliable negative correlation was observed between age and education for the whole sample $(r=-.42$, $\mathrm{p}<.01)$, for the women $(\mathrm{r}=-.44, \mathrm{p}<.001)$, and for the men $(r=-.38, p<.05)$. Education was positively correlated with health for the entire sample $(r=.30$, $\mathrm{p}<.01)$ and for women $(\mathrm{r}=.34, \mathrm{p}<.01)$, but the correlation for men between education and health was not significant $(r=.18)$. Fear of death was not significantly correlated with any of the other variables for the sample as a whole or for women and was significantly correlated with only life satisfaction and ego identity for men.

\section{DISCUSSION}

Erikson's contention that the eighth developmental crisis, ego integrity vs. despair, is more likely to be successfully resolved by those who have successfully resolved the earlier developmental crises was supported by the significant positive correlation obtained between our measures of ego identity and of life satisfaction. However, only partial support was obtained for the other two predictions tested. The hypothesized negative correlations between fear of death and ego identity and between fear of death and life satisfaction were obtained for the men tested, but not for the women. Assuming our results are replicable, it is not immediately apparent why the pattern of results differed for the two sexes. Education was the only demographic variable assessed on which men and women differed; however, the results of the partial correlation analyses would seem to indicate that the sex-related differences in education were not responsible for the observed differences.

Another way in which the two sexes probably differed was marital status. While marital status of the subjects was not assessed, it is extremely likely that the percentage of women not currently married was greater than that of men. While it is intuitively reasonable to suppose that marital status might be related to one's psychological functioning, the present data provide no support for such reasoning. Men and women did not differ in mean scores (with the exception of education) or in variability for any of the measures obtained in this study.

Perhaps the most likely explanation for the sex-related differences in our results involves the differing experiences of older adult life for most men and women. Most men of the generation tested have worked the majority of their adult lives, with their jobs often constituting an important component of their identities. At retirement, they may experience a dramatic change in their lifestyles, for which they may be unprepared. However, women, both those who have and those who have not been employed outside the home, may experience a much less dramatic change. For many women, the home and running of the household have been a central part of their lives and a source of their identities. As men are faced with the changes accompanying retirement, they must incorporate these changes into their identity and develop a continuing sense of satisfaction with their lives, including the acceptance of the inevitability of their death. Men are probably more acutely faced with a renewed identity crisis and reconfronted by issues of autonomy, initiative, and industry, so that their resolution of those earlier crises and their current feelings of life satisfaction may be more salient for them than for women. Women of this generation may experience a slightly different process. Gender is important only as it represents a line of demarcation of different life-styles within this generation. It is important to remember that men and women do not differ significantly on their levels of life satisfaction, ego identity, or fear of death, but they may have achieved the same levels by slightly different processes. If this interpretation of these results is correct, then women who do experience the sudden loss of a major source of their identity should also demonstrate a negative correlation between fear of death and life satisfaction and between fear of death and ego identity. A tentative conclusion that can be 
proposed based on these data is that Erikson's reflective theory may, in fact, apply more adequately to older adult men than to older adult women. In any event, subsequent research should focus on psychosocial aging processes separately for men and women.

The present study constitutes an initial examination of the utility and validity of Erikson's eighth developmental crisis. Further research in this area seems justified, as the despair/ego integrity continuum provides a theoretical framework for looking at adaptive aging. For various reasons, the elderly currently receive far less than their share of mental health services. As a group, they are facing problems of loneliness, bereavement, financial difficulties, health problems, and social isolation, yet they constitute only a very small percentage of the population seen at most mental health facilities. This underrepresentation of the elderly is a trend that may be altered in the future, as cohort groups that are more accepting of mental health services become older. As more older adults seek psychological services, a theoretical framework will be needed to provide professionals with increased understanding of the predictable conflicts that accompany the aging process. Erikson has attempted to provide one theoretical framework within which to conceptualize aging. An understanding of the common conflicts of aging gives a structure against which to evaluate the problems of an elderly client, and a delineation of the optimal resolution of the conflicts helps provide direction to the process of change.

\section{REFERENCES}

Adams, D. L. Analysis of a life satisfaction index. Journal of Gerontology, 1969, 24, 470-474.

Erikson, E. H. Childhood and society. New York: Norton, 1950.

Erikson, E. H. Identity and the life cycle: Selected papers. Psychological Issues, 1959, 1, 1-171.

Neugarten, B. L., Crotty, W. J., \& Tobin, S. S. Personality types in an aged population. In B. L. Neugarten (Ed.), Personality in middle and late life. New York: Atherton Press, 1964.

Neugarten, B. L., Havighurst, R. J., \& Tobin, S. S. The measurement of life satisfaction. Journal of Gerontology, 1961, 16, 134-143.

RASmussen, J. E. Relationship of ego identity to psychosocial effectiveness. Psychological Reports, 1964, 15, 815-825.

Reichard, S., Livson, F., \& Peterson, P. Aging and personality. New York: Wiley, 1962.

Spreitzer, E., \& SNyder, E. E. Correlates of life satisfaction among the aged. Journal of Gerontology, 1974, 29, 454-458.

TEMPLER, D. I. The construction and validation of a death anxiety scale. Journal of General Psychology, 1970, 82, 165-177.

(Received for publication August 12, 1981.) 